\title{
Composition Analysis on the Precipitates in the NiTiHf and NiPdTiHf Alloys
}

\author{
F. Yang ${ }^{1}$, A. Devaraj ${ }^{2}$, R.D. Noebe ${ }^{3}$, R.E.A. Williams ${ }^{1}$, M.J. Mills ${ }^{1}$, D.B. Williams ${ }^{1}$, D.W. McComb ${ }^{1}$ \\ 1. Department of Materials Science and Engineering, The Ohio State University, Columbus, OH 43210 \\ 2. EMSL, Pacific Northwest National Laboratory, Richland, WA 99354 \\ 3. NASA Glenn Research Center, Cleveland, OH 44135
}

Driven primarily by the needs of the aerospace industry, recent focus has been on the development of high temperature shape memory alloys (HTSMA) with transformation temperatures much higher than binary NiTi alloys could afford [1, 2]. The majority of the HTSMAs are obtained from alloying the binary NiTi alloys with a third element. The Ni-Ti-Hf/Zr alloys have received more attention, due to the lower cost for $\mathrm{Hf} / \mathrm{Zr}$ compared to precious metals and the significant influence of these alloying elements on the transformation temperatures [1,2]. A novel precipitate phase has been reported in Ni rich NiTiHf [3] and NiTiZr alloys [4]. The precipitate phase, known as the H-phase, was shown to influence the strength, dimensional stability, work output, and superelastic behaviors in Ni rich NiTiHf alloys [5]. An atomic structural model for the unit cell of the H-phase was proposed by Yang et al. by employing both characterization methods and ab initio calculations [6].

The H-phase composition has been analyzed by 3D atom probe tomography (APT), shown in figure 1. It was shown that compare to the matrix, the precipitates are Hf richer, Ti leaner and only slightly $(\sim 2$ at $\%)$ $\mathrm{Ni}$ richer. The slightly higher $\mathrm{Ni}$ concentration in the precipitates practically makes the martensite matrix $\mathrm{Ni}$ leaner, which may play a significant role in increasing the martensitic transformation temperatures of the alloy. Such a slight enrichment of $\mathrm{Ni}$ in the $\mathrm{H}$-phase may not show up unequivocally in traditional STEM-EDS line scans, due to the inherent uncertainty induced by the limited X-ray count rates. EDS analysis using the ChemiSTEM technology will be performed on the same alloy and the results will be compared to those from $3 \mathrm{D}$ APT.

Anti-phase boundaries (APBs) have been observed in large H-phase precipitates; HAADF STEM images indicate that composition at the APBs is different from that in the perfect crystal [6]. It was proposed that a large density of the APBs could therefore alter the average composition of the $\mathrm{H}$-phase [6]. Preliminary studies have shown that very small H-phase precipitates are APB-free. Therefore, it is likely that small H-phase precipitates will have a slightly different composition than large ones. It is of special interest to investigate if very small H-phase precipitates are also slightly Ni-rich.

$\mathrm{Ni}(\mathrm{Pd}) \mathrm{TiHf}$ alloys aged at lower temperature and/or for shorter time introduces another precipitate phase, termed H'-phase; preliminary studies shows $\mathrm{H}^{\prime}$-phase may be a precursor metastable phase that appears before the $\mathrm{H}$-phase at lower temperature aging $\left(400 \sim 500^{\circ} \mathrm{C}\right)$. Both precipitates exist in the $\mathrm{Ni}$ 5Pd-29.7Ti-20Hf (at \%) alloy aged at $500^{\circ} \mathrm{C}$ for 48 hours, shown in figure 2 . The very small size of these precipitates makes traditional S/TEM-EDS composition analysis difficult. The ChemiSTEM technology on the Titan 600-300 has the spatial resolution and much higher X-ray count rates, which enables us to determine more accurately the composition of precipitates of only a few nanometers in size.

References:

[1] Noebe RD, Biles T, Padula II SA. "NiTi-Based High-Temperature Shape-Memory Alloys:

Properties, Prospects, and Potential Applications, in Advanced structural materials: properties, design optimization, and applications", ed. T.S.S. Winston, O. Soboyejo, (CRC Press: Boca Raton, FL). 
[2] Ma J, Karaman I, Noebe RD. Inter. Mater. Rev 55 (2010), p.257.

[3] Han X, Wang R, Zhang Z, Yang D. Acta Mater 46 (1997), p.273.

[4] Sandu AM, Tsuchiya K, Yamamoto S, Todaka Y, Umemoto M. Scripta Mater 55 (2006), p.1079.

[5] Coughlin DR, Phillips PJ, Bigelow GS, Garg A, Noebe RD, Mills MJ. Scripta Mater 67(2012), p.112.

[6] Yang F, Coughlin DR, Phillips PJ, Yang L, Devaraj A, Kovarik L, Noebe RD, Mills MJ. Acta Mater (2013, in press)

[7] This work has been supported by the US Department of Energy, Office of Basic Energy Sciences under grant \#DE-SC0001258 (for FY and MJM). A part of this work was conducted in the William R. Wiley Environmental Molecular Sciences Laboratory (EMSL), a national scientific user facility sponsored by DOE's Office of Biological and Environmental Research and located at PNNL. PNNL is operated by Battelle for the DOE under Contract DE-AC05-76RLO1830.
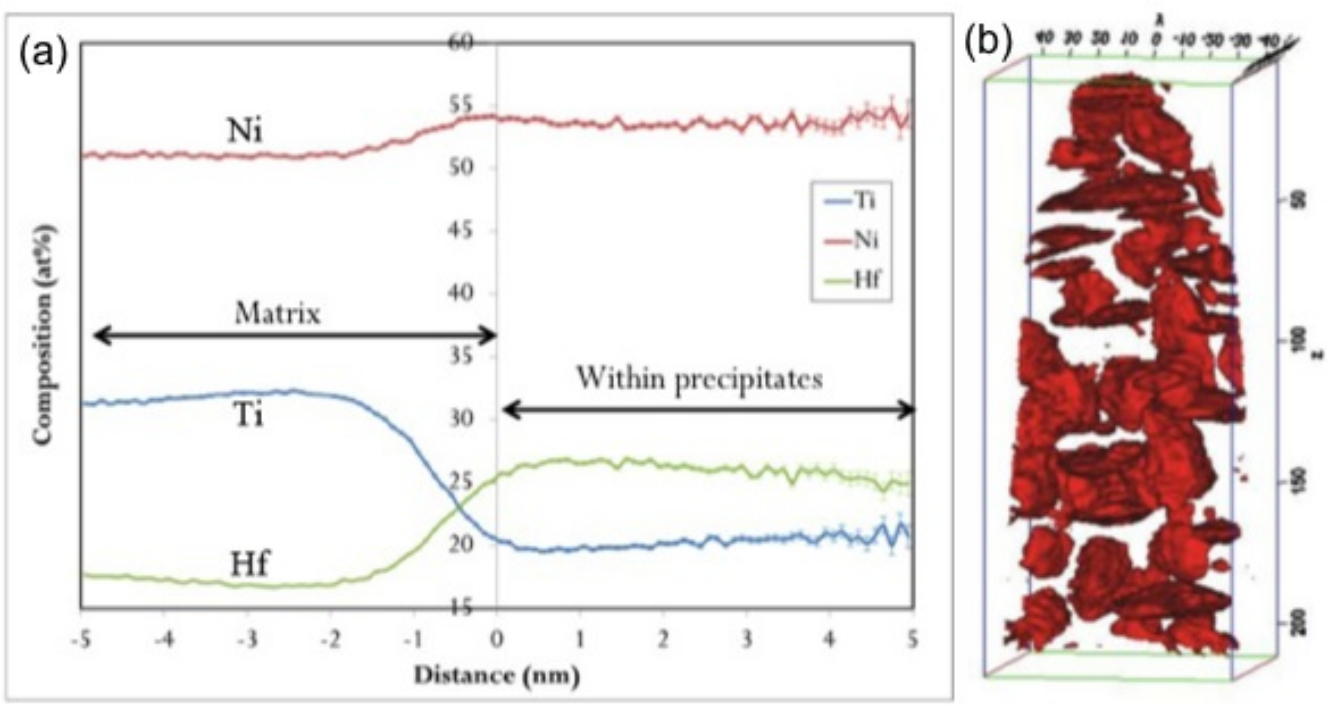

Figure 1. (a) Proximity histogram composition profile across the interface between the H-phase and the martensite matrix; (b) 23 at\% Hf iso-composition surface showing the H-phase in reconstructed volume.

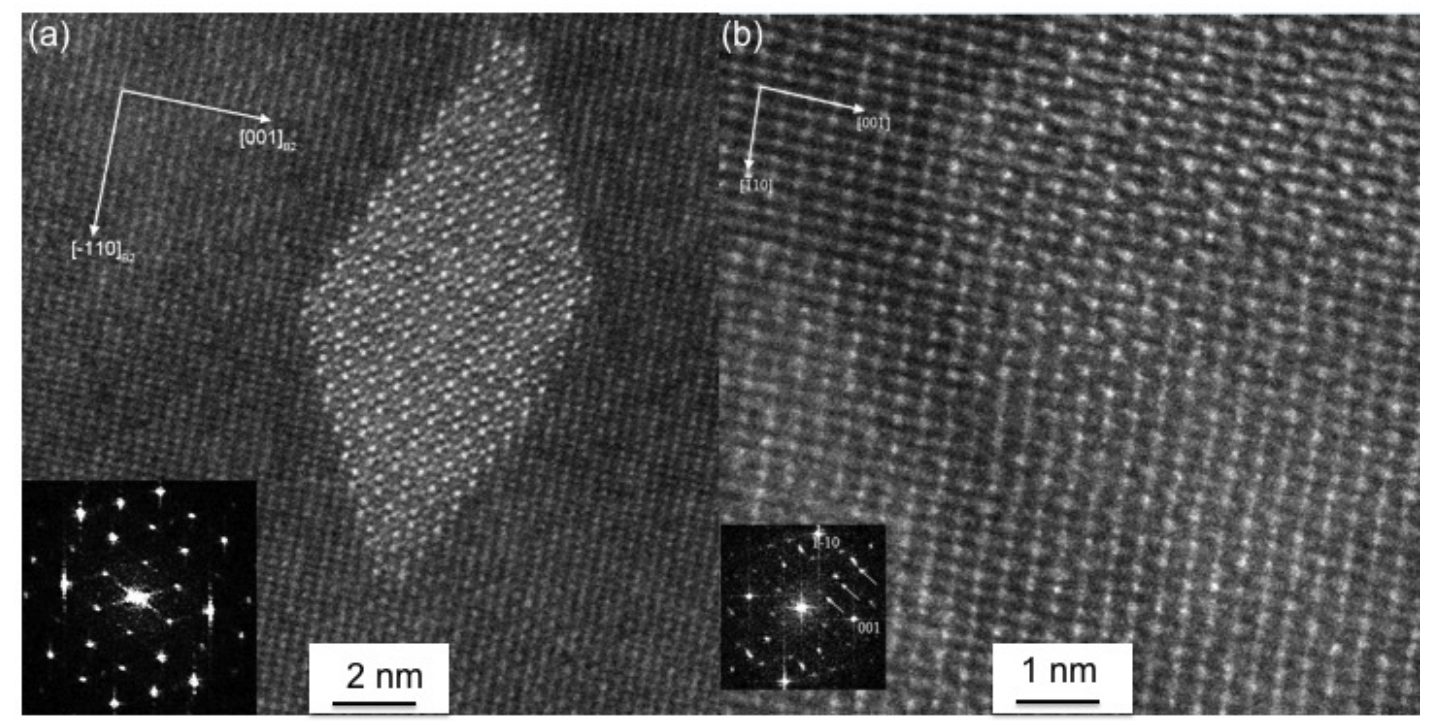

Figure 2. (a) H-phase and (b) $\mathrm{H}^{\prime}$-phase in the Ni-5Pd-29.7Ti-20Hf alloy aged at $500^{\circ} \mathrm{C}$ for 48 hours. 